\title{
Multisensory Integration Enhances Temporal Coding in Ventral Cochlear Nucleus Bushy Cells
}

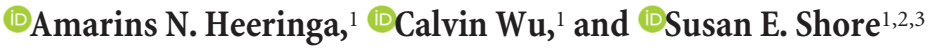 \\ ${ }^{1}$ Kresge Hearing Research Institute, Department of Otolaryngology, ${ }^{2}$ Department of Molecular and Integrative Physiology, and ${ }^{3}$ Department of Biomedical \\ Engineering, University of Michigan, Ann Arbor, Michigan 48104
}

Temporal coding of auditory stimuli is critical for understanding communication signals. The bushy cell, a major output neuron of the ventral cochlear nucleus, can "phase-lock" precisely to pure tones and the envelopes of complex stimuli. Bushy cells are also putative recipients of brainstem somatosensory projections and could therefore play a role in perception of communication signals because multisensory integration is required for such complex sound processing. Here, we examine the role of multisensory integration in temporal coding in bushy cells by activating the spinal trigeminal nucleus (Sp5) while recording responses from bushy cells. In normal-hearing guinea pigs of either sex, bushy cell single unit responses to amplitude-modulated (AM) broadband noise were compared with those in the presence of preceding Sp5 electrical stimulation (i.e., bimodal stimuli). Responses to the AM stimuli were also compared with those obtained $45 \mathrm{~min}$ after the bimodal stimulation. Bimodal auditory-Sp5 stimulation resulted in enhanced envelope coding for low modulation frequencies, which persisted for up to $45 \mathrm{~min}$. AM detection thresholds were significantly improved $45 \mathrm{~min}$ after bimodal auditory-Sp5 stimulation, but not during bimodal auditory-Sp5 stimulation. Anterograde labeling of Sp5 projections was found within the dendritic fields of bushy cells and their inhibitory interneurons, D-stellate cells. Therefore, enhanced AM responses and improved AM sensitivity of bushy cells were likely facilitated by Sp5 neurons through monosynaptic excitatory projections and indirect inhibitory projections. These somatosensory projections may be involved in the improved perception of communication stimuli with multisensory stimulation, consistent with psychophysical studies in humans.

Key words: bushy cells; multisensory; sound coding; temporal coding; ventral cochlear nucleus

\section{Significance Statement}

Multisensory integration is crucial for sensory coding because it improves sensitivity to unimodal stimuli and enhances responses to external stimuli. Although multisensory integration has typically been described in the cerebral cortex, the cochlear nucleus in the brainstem is also innervated by multiple sensory systems, including the somatosensory and auditory systems. Here, we showed that convergence of these two sensory systems in the cochlear nucleus results in improved temporal coding in bushy cells, principal output neurons that send projections to higher auditory structures. The improved temporal coding instilled by bimodal auditory-Sp5 stimulation may be important in priming the neurons for coding biologically relevant sounds such as communication signals.

\section{Introduction}

To achieve a comprehensive picture of the external world, the brain integrates information from multiple senses (Stein and Stanford,

Received Aug. 8, 2017; revised Jan. 29, 2018; accepted Feb. 5, 2018.

Author contributions: A.N.H. and S.E.S. designed research; A.N.H. and C.W. performed research; S.E.S. contributed unpublished reagents/analytic tools; A.N.H., C.W., and S.E.S. analyzed data; A.N.H., C.W., and S.E.S. wrote the paper.

This work was supported by the National Institutes of Health (Grant R01-DC004825 to S.E.S. and P30-DC05188). We thank Annabel Lemke, David Martel, and James Wiler for technical assistance; Sasha Meshinchi for assistance with confocal images; and the anonymous reviewers whose critical reviews have substantially improved the manuscript.

The authors declare no competing financial interests.

Correspondence should be addressed to Susan Shore, Kresge Hearing Research Institute, 1100 W. Medical Center Drive, Ann Arbor, Ml 48104. E-mail: sushore@umich.edu.
2008). Human psychophysical studies have shown that effective multisensory integration of these crossmodal inputs results in improved detection thresholds (Frassinetti et al., 2002; Bolognini et al., 2005; Caclin et al., 2011), a more salient percept (Stein et al., 1996; Foxe et al., 2000; Schürmann et al., 2004; Gillmeister and Eimer, 2007; Wilson et al., 2010), and faster reaction times (Murray et al., 2005; Sperdin et al., 2009).

Most studies of multisensory integration have focused on brain structures such as the superior colliculus, primary sensory cortices, and secondary cortical areas (Lakatos et al., 2007; Stein 
and Stanford, 2008; Alais et al., 2010). However, recent studies have shown that auditory processing in the brainstem is also influenced by other modalities including the somatosensory system. Injections of anterograde tracers into the spinal trigeminal nucleus (Sp5) revealed somatosensory projections throughout the cochlear nucleus (CN) (Li and Mizuno, 1997; Zhou and Shore, 2004; Haenggeli et al., 2005; Zhou et al., 2007; Zeng et al., 2011), but primarily in the granule cell domain (GCD), which encapsulates the ventral CN (VCN) and extends into the fusiform cell layer of the dorsal CN (DCN) (Zhou and Shore, 2004; Haenggeli et al., 2005). The $\mathrm{CN}$ is innervated primarily by neurons from the pars interpolaris (Sp5I) and pars caudalis (Sp5C) (Zhou and Shore, 2004), which receive somatosensory projections from mechanoreceptors in the jaw, scalp, and face, including the pinnae, eyelids, vibrissae, and vocal tract (Hayashi, 1980; van Ham and Yeo, 1996; Kanold and Young, 2001). Fusiform cells, the principal output neurons of the DCN, integrate auditory nerve (AN) input with multimodal inputs conveyed by granule cells of the GCD (Shore, 2005; Koehler et al., 2011; Barker et al., 2012; Koehler and Shore, 2013; Wu et al., 2016). However, the effects of stimulating the Sp5 projection on neurons in the magnocellular region of the VCN (Zhou and Shore, 2004; Haenggeli et al., 2005) have not been described.

Bushy cells are principal output neurons of the VCN. They can be further subdivided into two morphologically distinct types: spherical bushy cells (SBCs), which have spherical somata and one or two dendrites subdividing into a dense bush, and globular bushy cells (GBCs), which have elongated somata and less densely branching dendritic fields (Hackney et al., 1990). Bushy cells can be distinguished physiologically based on their responses to pure tones: SBCs typically show primary-like responses, whereas GBCs have typical primary-like with notch responses (Rhode et al., 1983; Rouiller and Ryugo, 1984; Smith and Rhode, 1987). Both SBCs and GBCs receive axosomatic terminations from the AN (Tolbert and Morest, 1982; Ryugo and Sento, 1991) and project to the superior olivary complex (SOC) (Smith et al., 1991; Smith et al., 1993; Cant and Benson, 2003) for binaural comparisons. Bushy cells exhibit strong phase locking to low-frequency fine structure and sound envelopes (Frisina et al., 1990b; Joris et al., 1994a; Joris et al., 2004). In fact, bushy cell amplitude-modulation detection thresholds are similar to human psychophysical detection thresholds (Sayles et al., 2013), further emphasizing the important role of these cells in temporal coding of sound stimuli. Human studies have demonstrated that temporal cues are important for recognizing biologically relevant sounds, including speech (Shannon et al., 1995). In this study, we investigated the function of the putative Sp5-to-VCN projection on bushy cell temporal acuity. Bimodal auditory-somatosensory stimulation was applied before and after sound-alone stimuli to examine the influence of multisensory integration on temporal coding. We found that the bimodal stimulation resulted in enhanced responses to amplitude-modulated (AM) stimuli and improved AM detection thresholds. These results suggest that auditory-somatosensory integration in VCN bushy cells is implicated in the improved perception of biologically relevant sounds with multisensory stimulation observed in psychophysical studies in humans (Alais et al., 2010).

\section{Materials and Methods}

Animals. Pigmented guinea pigs of either sex $(n=9,317-765$ g; Elm Hill Laboratories) were anesthetized with ketamine/xylazine (40 mg/kg, Putney; $10 \mathrm{mg} / \mathrm{kg}$, Lloyd, subcutaneous). Supplemental anesthesia was given approximately hourly to maintain a nonreflexive state in response to a
A

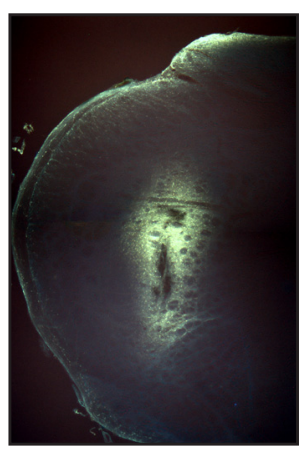

B

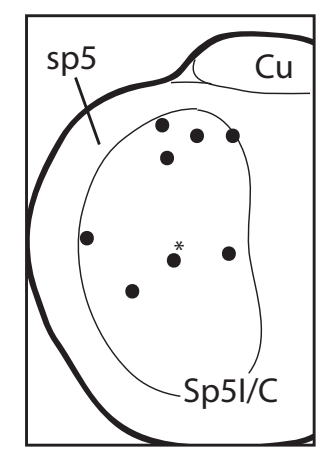

Figure 1. Confirmation of the stimulating electrode placement in Sp5. $\boldsymbol{A}$, Representative example of the Fluorogold-labeled electrode tract in the pars interpolaris of Sp5. B, Histological reconstruction of the placement of the $\mathrm{Sp5}$-stimulating electrode of $8 / 9$ animals. Asterisk indicates the electrode tract in $\boldsymbol{A}$.

hindpaw pinch. To fixate the head, animals were secured with hollow ear bars in a stereotaxic frame (Kopf Instruments). Body temperature was kept constant at $38.5^{\circ} \mathrm{C}$ with a custom-built heating pad and rectal probe. Experiments were conducted in a double-walled sound-attenuating booth. To ensure normal hearing thresholds, auditory brainstem responses were assessed before surgery $(0-90 \mathrm{~dB}$ sound pressure level [SPL] tone bursts in $10 \mathrm{~dB}$ steps, $30 \mathrm{~Hz}$ presentation rate, up to 1024 repetitions per intensity, $2-24 \mathrm{kHz}$ in octave-based steps; Tucker-Davis Technologies). All experimental procedures performed for this study were approved by the University Committee on Use and Care of animals at University of Michigan and are in accordance with protocols established by the National Institute of Health publication No. 80-23.

Neurophysiological recordings. A small craniotomy was made in the left parieto-occipital bone, followed by a duratomy. A two-shank, 16-or 32channel recording electrode (A2x8-11 mm-125-200-177 or A2x16-10 $\mathrm{mm}-50-500-177$; Neuronexus) was stereotaxically placed into the VCN through the intact cerebellum using preestablished coordinates $\left(35^{\circ}\right.$ angle caudal from vertical, $3 \mathrm{~mm}$ caudal from the interaural axis, $4.5 \mathrm{~mm}$ lateral from the midline, and 7-8 $\mathrm{mm}$ deep from the surface of the cerebellum). Ipsilaterally presented broadband noise bursts (65 dB SPL, $50 \mathrm{~ms}$ duration, $2 \mathrm{~ms}$ linear ramp rise/fall time) were used to locate units. To stimulate the somatosensory system, a concentric bipolar stimulating electrode (Frederick Haer \& Co.) was lowered into the left Sp5, targeting the $S p 5$ pars interpolaris (Sp5I) and the $S p 5$ pars caudalis (Sp5C) subdivisions, using stereotaxic coordinates $\left(0^{\circ}\right.$ vertical angle, $2.5 \mathrm{~mm}$ caudal from the transverse sinus, $2.8 \mathrm{~mm}$ lateral of the sagittal midline, $9 \mathrm{~mm}$ deep from the surface of the cerebellum). The occurrence of a small facial twitch when stimulating at current levels above threshold verified correct placement of the electrode in the Sp5. In addition, electrode placement was histologically verified postmortem (Fig. 1).

Signals recorded from the VCN electrode were amplified, digitized (25 kHz sampling rate), and filtered (bandpass $0.3-3 \mathrm{kHz}$ ) by a PZ2 preamplifier (Tucker-Davis Technologies). OpenEx software (TuckerDavis Technologies) was used to set a threshold and to store recorded spike timestamps and waveforms upon each threshold crossing. Waveforms were sorted using principal component analysis of the waveform shape using customized software in MATLAB (The MathWorks). Single unit clusters were selected based on visual inspection of the $3 \mathrm{D}$ clusters. Threshold crossings due to electrical artifacts from the Sp5 stimulating electrode were identified and excluded based on the timing of the electrical stimulation and the waveform shapes. Spike waveforms remained constant over the experiment.

Stimuli. To characterize the unit types in the VCN, data to construct receptive fields, peristimulus time histograms (PSTHs), spontaneous firing rates (SFRs), and noise rate-level functions (RLFs) were collected. Tone bursts (frequency of $0.2-32 \mathrm{kHz}$ in 0.15 octave steps; intensity of $0-90 \mathrm{~dB}$ in $5 \mathrm{~dB}$ steps; $50 \mathrm{~ms}$ duration, 2 ms linear ramp; 5 repetitions of each tone bursts) were presented for construction of the receptive fields. 
Subsequently, 300 repetitions of tone bursts at best frequency (BF; $20 \mathrm{~dB}$ and $50 \mathrm{~dB}$ above threshold, $50 \mathrm{~ms}$ duration, $2 \mathrm{~ms}$ linear ramp) were presented to collect data for PSTHs and $450 \mathrm{~s}$ of SFR was collected. Broadband noise bursts ( $0-90 \mathrm{~dB}$ in $5 \mathrm{~dB}$ steps; $50 \mathrm{~ms}$ duration, $2 \mathrm{~ms}$ linear ramp; 50 repetitions per intensity) were presented to construct noise RLFs. Tone RLFs were derived from receptive fields at BF.

Sp5 stimulation consisted of three biphasic (100 $\mu$ s/phase) current pulses presented at $1000 \mathrm{~Hz}$. A search stimulus with linearly increasing current steps from 0 to $90 \mu \mathrm{A}$ in $10 \mu \mathrm{A}$ steps was used to determine the highest current amplitude that did not elicit a movement artifact. This level was used throughout the experiment for unimodal Sp5 and bimodal auditory-Sp5 stimulation (mean: $30 \mu \mathrm{A}$, range: 6-60 $\mu \mathrm{A}$ ). Subsequently, responses to different levels of broadband noise bursts were used to determine a noise level that was at least $10 \mathrm{~dB}$ above threshold for all channels with VCN units. Broadband noise at that level was multiplied with $s(t)$ to obtain sinusoidal AM broadband noise as follows:

$$
s(t)=1+m \sin (2 \pi f t)
$$

where $m$ represents modulation depth $(m=0 \%, 6 \%, 13 \%, 25 \%, 50 \%$, and $100 \%)$ and $f$ represents modulation frequency $(f=8-2048 \mathrm{~Hz}$ in 1 -octave or 0.5 -octave steps, $400 \mathrm{~ms}$ duration, 100 repetitions per $f$ ). Next, these stimuli were preceded by $10 \mathrm{~ms}$ with $\mathrm{Sp} 5$ stimulation, to determine auditory-somatosensory bimodal integration (e.g., see Fig. $4 B)$.

To determine bimodal plasticity (i.e., the persistent effects), AM noise with the same parameters was presented before and $45 \mathrm{~min}$. after bimodal auditory-Sp5 stimulation, which consisted of unmodulated noise bursts ( $50 \mathrm{~ms}, 0-90 \mathrm{~dB}$ SPL, 50 repetitions) that were preceded by $10 \mathrm{~ms}$ with Sp5 stimulation. In the sham condition, all parameters were kept the same, except that the $\mathrm{Sp} 5$ stimulator was disconnected.

Data analysis. Single unit receptive fields were plotted to determine BF, threshold, and Q10 dB (tuning width $10 \mathrm{~dB}$ above threshold). Bushy cells were classified based on their typical primary-like (Pri; for SBCs) or primary-like with notch (Pri-N; for GBCs) temporal discharge patterns and relative high coefficients of variation in response to BF tone bursts 20 $\mathrm{dB}$ and $50 \mathrm{~dB}$ above threshold, their SFR, and RLFs for BF tone bursts and noise bursts (Young et al., 1988; Blackburn and Sachs, 1989; Winter and Palmer, 1990, 1995; Ingham et al., 2016). D-stellate cells were classified based on their typical onset-chopper (on-C) temporal discharge pattern to BF tone bursts $20 \mathrm{~dB}$ and $50 \mathrm{~dB}$ above threshold, their SFRs, and RLFs in response to BF tone bursts and noise bursts (Smith and Rhode, 1989). Bushy cells can also be distinguished from other cells in the VCN by the presence of a characteristic prepotential, representing depolarization of the presynaptic endbulb of Held (Keine and Rübsamen, 2015). Because we used an electrode with 1-3 $\mathrm{M} \Omega$ impedance and a site area of $177 \mu \mathrm{m}^{2}$, prepotentials could only be observed when the signal-to-noise ratio was considerably high. Therefore, the presence of a prepotential was not consistently used as a classification marker. However, all units classified as On-C indeed lacked a prepotential, whereas prepotentials were occasionally observed in Pri units. To determine the presence of unimodal $\mathrm{Sp} 5$ responses, firing rates before, during, and after $\mathrm{Sp} 5$ stimulation were plotted (bin width $0.2 \mathrm{~ms}$ ). Mean and SDs of SFR were calculated over the $100 \mathrm{~ms}$ time window preceding each Sp5 stimulation. Excitatory Sp5 responses were defined by the presence of at least 4 bins within a $10 \mathrm{~ms}$ time window after Sp5 stimulation with $>3$ STD above mean SFR. Inhibitory responses were not observed. Response latencies relative to the initiation of unimodal Sp5 stimulation were calculated using the method developed by Chase and Young (2007).

The tendency of a unit to phase lock to the amplitude modulation of the stimulus was expressed by the synchronization index (SI) as follows:

$$
S I=\frac{1}{N}\left|\sum_{j=1}^{N} e^{i \varphi(j)}\right|,
$$

where $N$ is the number of spikes, $i$ is the complex number $V(-1)$, and $\varphi(j)$ is the phase of the $j$-th spike relative to the sinusoidal amplitude modulation $s(t)$ of the acoustic stimulus. The SI is equivalent to the vector strength (Goldberg and Brown, 1969) and represents a normalized estimate of a unit's tendency to fire at a particular phase in a stimulus cycle. Only spikes during the steady phase of the stimulus response were taken into account (from $25 \mathrm{~ms}$ after stimulus onset until stimulus offset). SI values were submitted to the Rayleigh statistics (RS) to determine statistical significance (RS $>13.8$, i.e., $p<0.001$, was considered statistically significant) (Mardia and Jupp, 2000):

$$
R S=2 N\left(S I^{2}\right) .
$$

Response gain (in $\mathrm{dB}$ ), which represents the neural response gain relative to the stimulus modulation depth ( $m$ in \%), was calculated by the following:

$$
\text { Response gain }=20 \log _{10}\left(\frac{200 \times S I}{m}\right) \text {. }
$$

Modulation transfer functions (MTFs) were constructed by plotting SI versus modulation frequency $f$ at a particular modulation depth $m$. Best modulation frequency (BMF) was defined as the $f$ that elicited the maximum SI value in the MTF.

AM detection thresholds were determined using a neurometric analysis that successfully determined AM detection thresholds for VCN units (Sayles et al., 2013). Briefly, the phase-projected vector strength ( $\mathrm{VS}_{\mathrm{pp}}$ ) was calculated for each trial of each stimulus as follows:

$$
V S_{p p}(t)=\cos \left(\varphi_{t}-\varphi_{c}\right)\left(\frac{\sqrt{\left(\sum_{j=1}^{N} \cos \theta_{j}\right)^{2}+\left(\sum_{j=1}^{N} \sin \theta_{j}\right)^{2}}}{N}\right),
$$

in which $\varphi_{\mathrm{t}}$ is the mean phase of spikes in the $t$-th trial and $\varphi_{\mathrm{c}}$ is the mean phase of the spikes in all trials combined of that same stimulus. Subsequently, the $\mathrm{VS}_{\mathrm{pp}}$ of all trials in a certain stimulus condition (same $f$ and $m$ ) were compared with the $\mathrm{VS}_{\mathrm{pp}}$ calculated from the trials at that same $f$ when modulation depth $m$ was $0 \%$; that is, unmodulated noise. For each stimulus condition, a receiver operating curve (ROC) was constructed plotting the proportions of true-positive and false-positive classifications. The area under the ROC curve represents the probability of a randomly selected trial of the modulated signal having a $\mathrm{VS}_{\mathrm{pp}}$ greater than a randomly selected unmodulated trial and ranges from 0 to 1 . This value was determined for and plotted against each $m$ for one modulation frequency at the time, and fitted with the logistic function as follows:

$$
y=a+\left(\frac{b}{1+\exp \left(\frac{x-\mu}{s}\right)}\right) .
$$

The modulation depth $m$ where the fitted line crosses a threshold of 0.75 represents the AM detection threshold for that unit at that particular modulation frequency. Subsequently, detection threshold curves were determined by plotting the detection thresholds against modulation frequency $f$.

Experimental design and statistical analysis. In this study, a distinction was made between the immediate and long-term effects of bimodal auditory-Sp5 stimulation; that is, between bimodal integration and bimodal plasticity, respectively. To determine bimodal integration of auditory-Sp5 stimulation in bushy cells, BMF, synchronization indices at various modulation frequencies $(f=8-2048 \mathrm{~Hz})$, and AM detection thresholds were evaluated when auditory-alone stimuli were presented and compared with values when each auditory stimulus was preceded by Sp5 stimulation. BMF and synchronization indices below, at, and above BMF were evaluated for auditory-alone and auditory-somatosensory stimulation, using one-sample Student's $t$ tests. A Spearman's crosscorrelation was applied to determine correlations between BMF and the SI change at BMF due to bimodal integration. A nonparametric Wilcoxon rank-sum test and one-sample $t$ test was performed to determine differences between auditory-only and bimodal auditory-Sp5 stimulation AM detection thresholds. Similar analyses were performed to evaluate effects of bimodal plasticity (long-lasting effects) on BMF, SI indices at various modulation frequencies, and AM detection thresholds by comparing before and after bimodal auditory-Sp5 stimulation. In addition, to evaluate the long-term effects of bimodal auditory-Sp5 stim- 

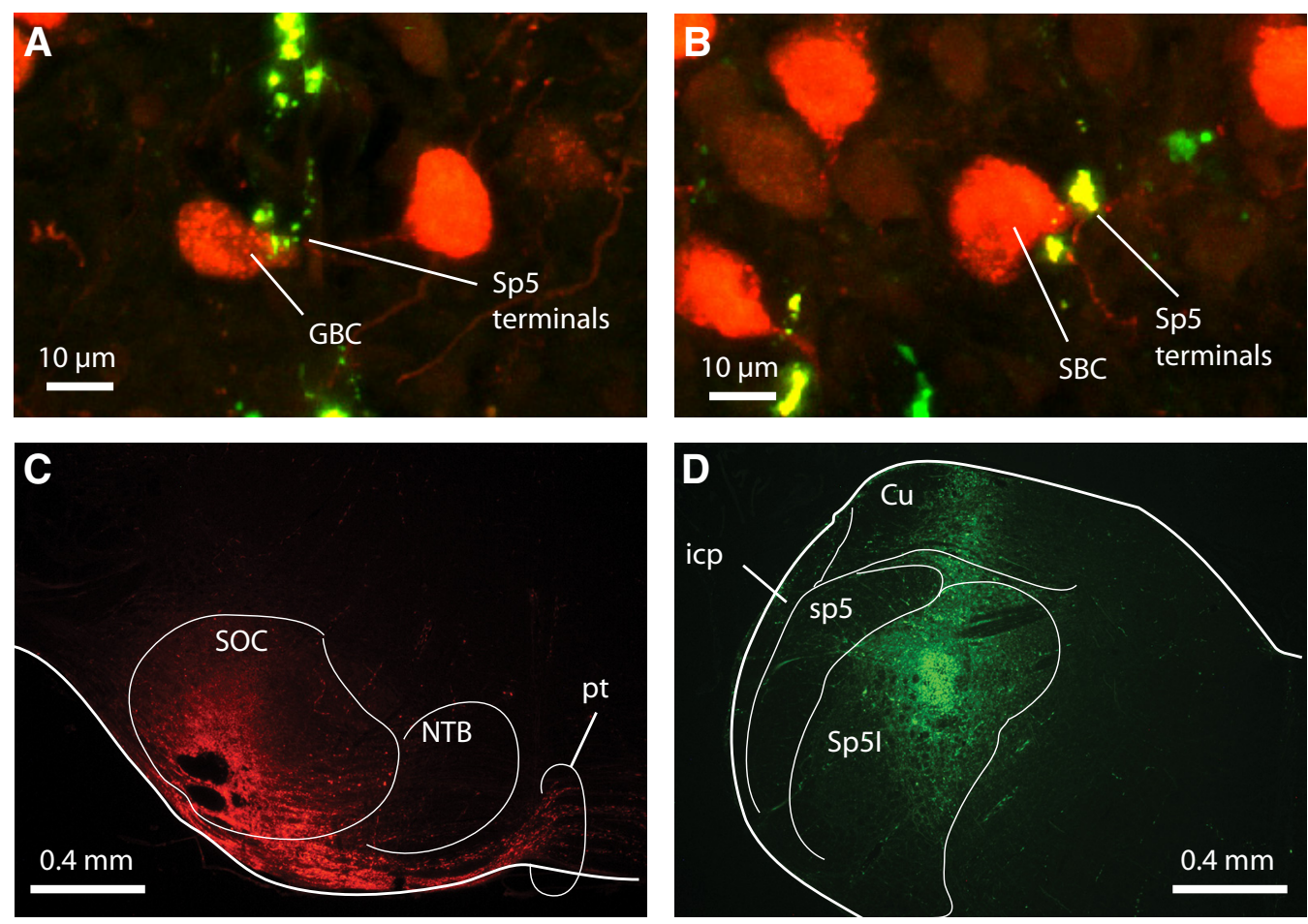

Figure 2. Sp5 projects to bushy cells dendritic regions in magnocellular VCN. $A$, Confocal photomicrograph of a putative GBC (red) in caudal AVCN with adjacent Sp5 en passant boutons (green) after FluoroEmerald injection in Sp5I. Bushy cell was back-labeled by SOC injection shown in C. B, Confocal photomicrograph of a putative SBC (red) in rostral AVCN with adjacent Sp5 mossy-fiber-like terminals. Double labeling (yellow) indicates that Sp5 terminates axodendritically in the dendritic field of the bushy cells. C, Photomicrograph of the FluoroRuby injection in SOC. D, Photomicrograph of the FluoroEmerald injection site in the left Sp5I. The core of the injection site was confined to the Sp5I, whereas the diffusion area spread out to parts of the cuneate nucleus. Cu, Cuneate nucleus; icp, inferior cerebellar peduncle; NTB, nucleus of the trapezoid body; pt, pyramidal tract; Sp5l, pars interpolaris of spinal trigeminal nucleus.

ulation on AM detection thresholds, changes in AM detection thresholds 45 min after bimodal auditory-Sp5 stimulation were compared with changes in AM detection thresholds after an auditory sham condition using a $\chi^{2}$ test. All $p$-values were Holm-Bonferroni corrected for multiple comparisons.

Histology. To determine the Sp5 stimulating electrode placement, after the experiment, it was extracted from the brain, dipped in 2\% FluoroGold, and replaced at the same absolute depth for 5 min while passing current through the electrode. After the electrode removal, the animal was killed with pentobarbital sodium (Med-Pharmex; intraperitoneal) and was transcardially perfused with $100 \mathrm{ml}$ of $0.1 \mathrm{M}$ PBS, pH 7.4, followed by $400 \mathrm{ml}$ of paraformaldehyde (4\% in PBS). The brain was removed from the skull and postfixated for $2 \mathrm{~h}$ in paraformaldehyde before being washed in PBS and immersed in 30\% sucrose solution. Brains were frozen, cryosectioned at $40 \mu \mathrm{m}$ (Leica, CM3050S), placed on glass slides, dehydrated, coverslipped, and examined using a fluorescence microscope (Leica, DMLB). The locations of the stimulating electrode in Sp5 are shown in Figure 1.

Six guinea pigs (400-500 g, Elm Hill Laboratories) were used to identify Sp5 projections to the VCN. Animals were anesthetized with ketamine/xylazine (40 mg/kg, Putney; $10 \mathrm{mg} / \mathrm{kg}$, Lloyd; subcutaneous) and placed in a stereotaxic frame (Kopf). A small longitudinal incision was made over the parietal bones and a small opening in the skull was drilled to allow for the Sp5 injection $(2.2 \mathrm{~mm}$ left of the midline and $4.1 \mathrm{~mm}$ caudal of the ear bar). A Hamilton microsyringe was loaded with $10 \%$ FluoroEmerald (Thermo Fisher Scientific) and placed into the Sp5 at a depth of $9 \mathrm{~mm}$ from the surface of the dura. A total volume of $0.5 \mu \mathrm{l}$ tracer was slowly injected over $5 \mathrm{~min}$, using a MicroSyringe Pump Controller (Micro 4; World Precision Instruments). In four animals, an additional opening was drilled at $2.5 \mathrm{~mm}$ left of the midline and at the rostral-to-caudal level of the ear bar to allow for an injection into the SOC. A volume of $0.5 \mu$ l of FluoroRuby (10\%; Thermo Fisher Scientific) was injected into the SOC $11 \mathrm{~mm}$ ventral from the dural surface over 5 min. In two other animals, FluoroRuby was injected into the contralat- eral CN instead of the SOC to label D-stellate cells, which form part of the CN-commissural pathway (Schofield and Cant, 1996). Subsequently, the animal was sutured and allowed to recover. Five days after surgery, the animal was killed with pentobarbital sodium and transcardially perfused with $100 \mathrm{ml}$ of PBS, followed by $400 \mathrm{ml}$ of paraformaldehyde (4\% in PBS). Processing of the brain was performed as described above.

Sp5 electrode locations, marked by Fluorogold deposits, and tracer injection sites were visualized and photographed with a fluorescence microscope (Leica, DMLB) and attached camera (Micropublisher, QImaging). Sp5 terminals, backfilled bushy cells, and backfilled D-stellate cells were examined and photographed with a camera attached to a confocal microscope (PMT; Leica, SP5-x). SBCs and GBCs were identified using characteristics defined by Osen (1969).

\section{Results}

Bushy cells receive excitatory projections from $\mathrm{Sp} 5$

Anterograde labeling from the FluoroEmerald Sp5 injection was observed throughout the magnocellular domain of the posterior and anterior VCN. The labeled puncta were in the form of small en passant and terminal boutons, as well as some larger puncta, consistent with mossy-fiber terminal endings (Zhou and Shore, 2004). Some Sp5 puncta were located in the dendritic fields of both GBCs (Fig. 2A) and SBCs (Fig. 2B), which were identified by retrograde labeling after FluoroRuby injections in their targets in SOC (Fig. 2C). Previous studies have shown that Sp5 terminals in the $\mathrm{CN}$ co-label with vesicular glutamate transporter 2 (VGLUT2) (Zhou et al., 2007; Zeng et al., 2011), confirming that these puncta are glutamatergic.

Excitatory responses to unimodal $\mathrm{Sp} 5$ stimulation were observed in $19 \%$ of Pri units $(n=21 / 110)$ and in $28 \%$ of Pri-N units $(n=28 / 104)$, confirming that the Sp5 inputs are glutamatergic and excitatory. Figure 3 shows representative examples of a uni- 
modal Sp5 response in a Pri (Fig. 3A) and Pri-N (Fig. 3B) unit. Responses consisting of multiple peaks (Fig. $3 A$ ) or a single peak of excitation (Fig. $3 B$ ) were observed in both unit types. Units responding with a single peak to unimodal Sp5 stimulation had significantly higher $\mathrm{BFs}(16.2 \mathrm{kHz} \pm$ 0.2 SEM) than units responding with multiple peaks $(9.5 \mathrm{kHz} \pm 0.1 \mathrm{SEM}$; 2-sample Kolmogorov-Smirnov [KS] test: $\mathrm{D}=0.4700, p=0.0055)$. Pure-tone thresholds, Q10dB, spontaneous firing rates, response latencies, response amplitudes, and $\mathrm{CN}$ depths did not differ significantly between units responding with a single peak and units responding with multiple peaks to Sp5 stimulation (2sample KS test: $\mathrm{p}=\mathrm{ns}$ for all comparisons). No inhibitory responses were observed. Mean excitatory response latency relative to initiation of $\mathrm{Sp} 5$ stimulation was $3.8 \pm 0.1 \mathrm{~ms}(\mathrm{SEM})$ and did not differ between single- or multiple-peaked responses.

Figure 3,C and $D$, show the BF and threshold distributions of units with and without an excitatory response to Sp5 stimulation in Pri (Fig. $3 C$ ) and Pri-N units (Fig. 3D). Units responding to Sp5 had significantly higher BFs $(13 \mathrm{kHz} \pm$ 1.15 SEM) than units that did not respond to $\mathrm{Sp} 5$ stimulation $(9.4 \mathrm{kHz} \pm 0.4 \mathrm{SEM}$; 2 -sample KS test: $\mathrm{D}=0.2911, p=0.002)$ and also had higher SFRs (2-sample KS test: $\mathrm{D}=0.2581, p=0.009)$. Pure-tone thresholds, Q10dB, and CN depths did not differ significantly between units with and without significant Sp5 responses (two-sample KS test: $p=$ ns for all comparisons). Because the responses of Pri and Pri-N units to Sp5 stimulation were similar in terms of prevalence, response latency, and response amplitude, Pri and Pri-N units were combined in subsequent analyses and termed PL units.

\section{AM coding but not AM detection thresholds are altered during auditory-Sp5 stimulation}

PL units responded robustly to AM noise. Figure $4 A$ shows a PSTH for an exemplary PL unit in response to $16 \mathrm{~Hz}$ AM noise with a modulation depth of $m=25 \%$ (Fig. $4 A$, orange line). The SI of this response was 0.25 , corresponding to a response gain of $6.0 \mathrm{~dB}$ relative to the stimulus modulation. When Sp5 stimulation preceded the auditory stimulus (Fig. $4 B$, green bar), this unit showed stronger phase locking to the stimulus envelope, with an SI of 0.33 , corresponding to a response gain of $8.43 \mathrm{~dB}$ (Fig. $4 B$ ). Across the population units, mean SI for $16 \mathrm{~Hz}$ AM noise was 0.22 (corresponding to a response gain of $4.98 \mathrm{~dB}$ ) and was significantly increased to an SI of 0.24 (response gain of $5.92 \mathrm{~dB}$ ) by auditoryare identical to $\boldsymbol{C}$.
A

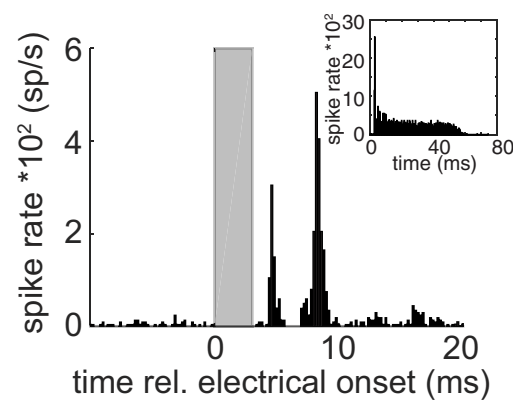

C

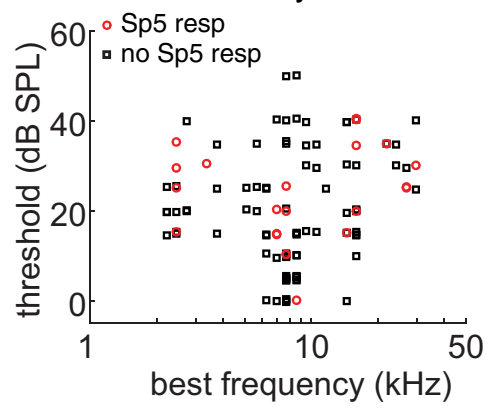

B

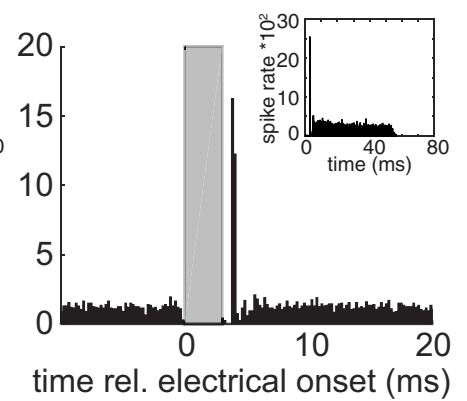

D

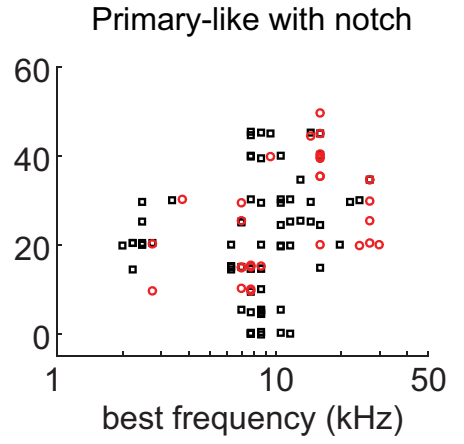

Figure 3. Unimodal Sp5 stimulation elicits excitatory responses in PL units. A, PSTH (0.2 ms bin width) of a double-peaked response of a Pri unit to electrical stimulation of Sp5 (three biphasic $40 \mu \mathrm{A}$ current pulses at $1000 \mathrm{~Hz}$ ). Inset shows the primary-like response to a BF tone burst ( $50 \mathrm{~ms}$ tone at $2.4 \mathrm{kHz}$ at $50 \mathrm{~dB}$ re threshold, $0.2 \mathrm{~ms}$ bin width). Gray bar indicates the Sp5 stimulus duration. The absence of neural activity from $0-2.2 \mathrm{~ms}$ is due to electrical artifact removal. $B$, PSTH (0.2 ms bin width) of a one-peaked response of a Pri-N unit to Sp5 stimulation (three biphasic $60 \mu \mathrm{A}$ current pulses at $1000 \mathrm{~Hz}$ ). Inset shows the primary-like with notch response to a tone burst at BF (50 ms tone at $16 \mathrm{kHz}$ at $30 \mathrm{~dB}$ threshold, $0.2 \mathrm{~ms}$ bin width). C, Threshold distribution across BF for all Pri units $(n=110)$ showing units with (red circles) and units without (black squares) a significant excitatory response to unimodal Sp5 stimulation. $\boldsymbol{D}$, Threshold distribution across BF for all Pri-N units $(n=104)$. Legend entries
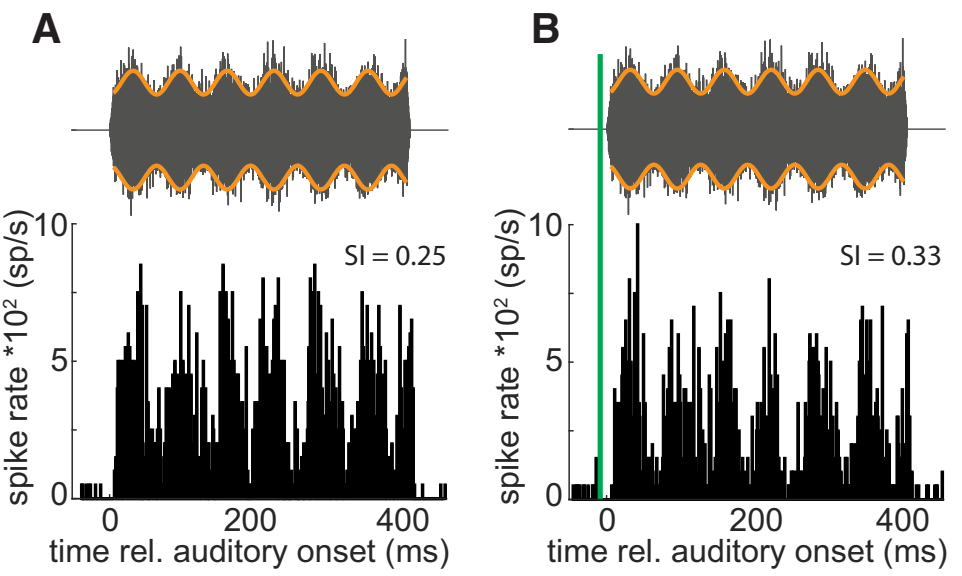

Figure 4. Bimodal auditory-Sp5 stimulation enhances envelope coding in a bushy cell. $A$, PSTH of the response of a Priunit to AM noise. The auditory stimulus is depicted above the histogram. The orange line represents the sinusoidal amplitude modulation of $16 \mathrm{~Hz}$, with a modulation depth $m$ of $25 \%$. Sl of the response to AM of this unit equals 0.25 . $\boldsymbol{B}$, PSTH of the response to bimodal auditory-somatosensory stimulation. The PSTH is derived from the same Pri unit as in $\boldsymbol{A}$. The green bar indicates the timing of the Sp5 stimulation, which preceded the onset of the AM noise by $10 \mathrm{~ms}$. The $\mathrm{SI}$ of the response to auditory-Sp5 stimulation equals 0.33 .

Sp5 stimulation (one-sample $t$ test: $t_{(97)}=2.658, p=0.0092$ ). Therefore, combining auditory and Sp5 stimulation enhances envelope coding to $16 \mathrm{~Hz}$ AM noise in PL units.

Across the range of modulation frequencies $(f=8-2048 \mathrm{~Hz})$, we found that bimodal auditory-Sp5 stimulation altered AM coding differentially at each modulation frequency. Preceding AM stimuli with Sp5 stimulation enhanced SIs at modulation 
A

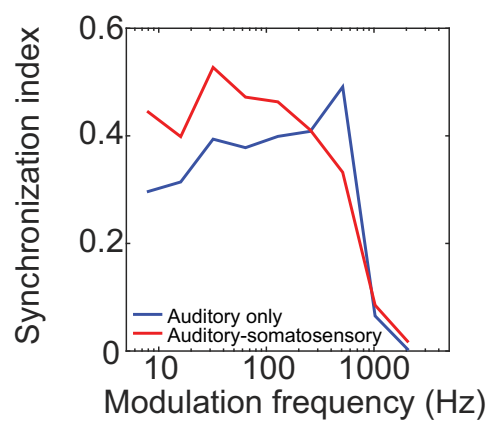

C

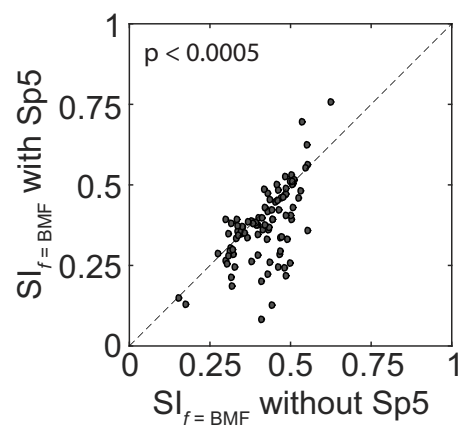

E

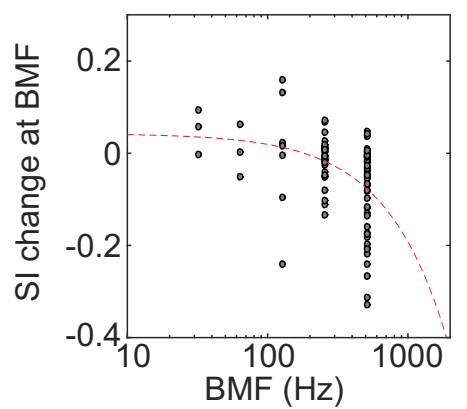

B

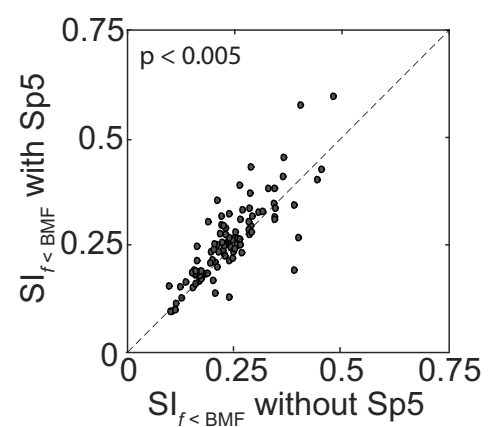

D

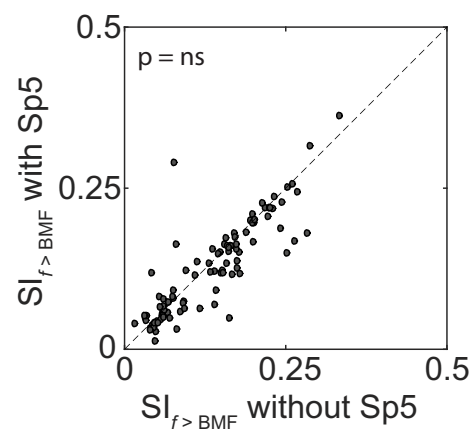

$\mathbf{F}$

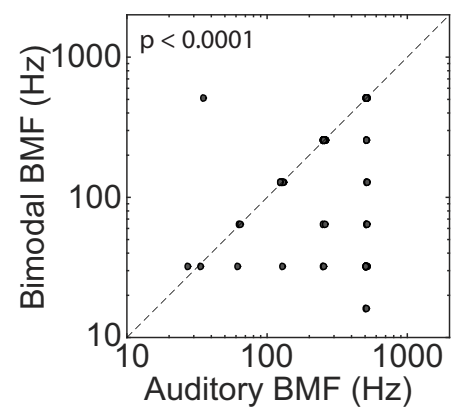

Figure 5. Effects of bimodal integration on the MTF. $\boldsymbol{A}$, Representative example of a Pri unit MTF before (blue line) and during (red line) bimodal auditory-Sp5 stimulation. $\boldsymbol{B}$, Mean SI plotted against mean SI during bimodal auditory-Sp5 stimulation for frequencies below BMF. C, SI at BMF plotted against SI at BMF during bimodal auditory-Sp5 stimulation. D, Mean SI plotted against mean SI during bimodal auditory-Sp5 stimulation for frequencies above BMF. $\boldsymbol{E}$, BMF plotted against the change in SI at BMF. The red dotted line is a linear fit function, described by $y=-0.0002^{*} x+0.0428$. F, BMF plotted against BMF during bimodal auditory-Sp5 stimulation. Black dotted lines in $\boldsymbol{B}-\boldsymbol{D}$ and $\boldsymbol{F}$ represent $y=x . p$-values depicted in the graphs indicate significance after one-sample $t$ tests and are corrected for multiple comparisons using the Holm-Bonferroni correction.

frequencies below BMF and decreased the SI at BMF, but did not affect SIs of frequencies above the initial BMF. Figure $5 A$ shows an example in which Sp5-preceding AM stimulation shifts a bushy cell MTF to the left. Across the population of units, the mean SI for modulation frequencies below BMF was significantly increased during bimodal auditory-Sp5 stimulation compared with AM-only stimulation (one-sample $t$ test: $t_{(97)}=3.64, p=$ $4.421^{\star} 10^{-4}$, Holm-Bonferroni correction for multiple comparisons; Fig. $5 B$ ). Conversely, SI at BMF was significantly decreased in response to bimodal auditory-Sp5 stimulation $\left(t_{(97)}=4.65, p=\right.$ $1.064^{\star} 10^{-5}$; Fig. $5 C$ ). The change in SI at BMF was significantly correlated with the initial BMF (Spearman's cross-correlation: $r=$ $\left.-0.443, p=5.057^{\star} 10^{-6}\right)$, so that units with high BMFs showed larger decreases in SI than units with lower BMFs (Fig. 5E). The data are described by the following function: change in SI =
$-0.0002 * \mathrm{BMF}+0.0428$ (red dotted line in Fig. 5E). Mean SI for modulation frequencies above BMF was not affected by bimodal auditory-Sp5 stimulation $\left(t_{(97)}=\right.$ 1.99, $\mathrm{p}=$ ns; Fig. 5D). MTF tuning was shifted to lower frequencies when AM stimuli were preceded by Sp5 stimulation $\left(t_{(97)}=5.36, p=5.506^{*} 10^{-7}\right.$; Fig. $\left.5 A, F\right)$.

Changes in synchronization index at different modulation frequencies during bimodal auditory-Sp5 stimulation were similar across modulation depths ( $m$ ranging from $100 \%$ to $6 \%$ ), but were most pronounced at the $25 \%$ modulation depth.

Bushy cell AM best detection thresholds (Fig. 6A) and AM detection threshold curves (Fig. 6A, inset) were similar to those reported by Sayles et al. (2013) (mean, 6.2\%; range, 2.5-33.1\%; SD, $3.6 \%)$. The distribution of best detection thresholds during bimodal auditory-Sp5 stimulation, in which Sp5 stimulation preceded AM stimuli, was similar to that of AM-only detection thresholds (mean, 5.7\%; range, $2.8-11.2 \%$; SD, $1.6 \%$; Wilcoxon rank-sum test: $Z=0.0712, \mathrm{p}=\mathrm{ns}$; Fig. 6B). Mean AM detection thresholds were not significantly altered during bimodal auditory-Sp5 stimulation, compared with AM-only stimulation (onesample $t$ test: $t_{(87)}=1.03, \mathrm{p}=\mathrm{ns}$ ). However, AM detection thresholds of bushy cells improved $45 \mathrm{~min}$ after bimodal stimulation (see below). This indicates that bushy cell's AM detection thresholds are likely affected through a slow acting modulatory rather than a direct-activation by bimodal auditorySp5 stimulation.

\section{AM coding is enhanced and AM detection thresholds are improved in bushy cells $45 \mathrm{~min}$ after bimodal stimulation}

When evaluating the MTF of a bushy cell before and 45 min after bimodal auditory-Sp5 stimulation (bimodal plasticity), SIs at modulation frequencies below the BMF remained improved (as during bimodal stimulation), whereas SI at BMF and SIs above BMF were not affected (example shown in Fig. 7A). Across the population of units, the mean SI for modulation frequencies below BMF was significantly decreased after bimodal auditory-Sp5 stimulation (one-sample $t$ test: $t_{(119)}$ $=7.24, p=4.833^{\star} 10^{-11}$, Holm-Bonferroni corrected for multiple comparisons; Fig. $7 B$ ). However, SI at BMF and SIs at modulation frequencies above BMF were not significantly changed after bimodal auditory-Sp5 stimulation $\left(t_{(119)}=2.27, \mathrm{p}=\mathrm{ns}\right.$, Fig. $7 C$, and $t_{(119)}=2.19, p=n s$, Fig. $7 D$, respectively). The correlation for BMF with SI change for bimodal integration (Fig. $6 E$ ) was no longer evident for bimodal plasticity (Fig. 7E), corresponding to the absence of a significant change in SI at BMF 45 min after bimodal auditory-Sp5 stimulation (Fig. 7C). BMF was 

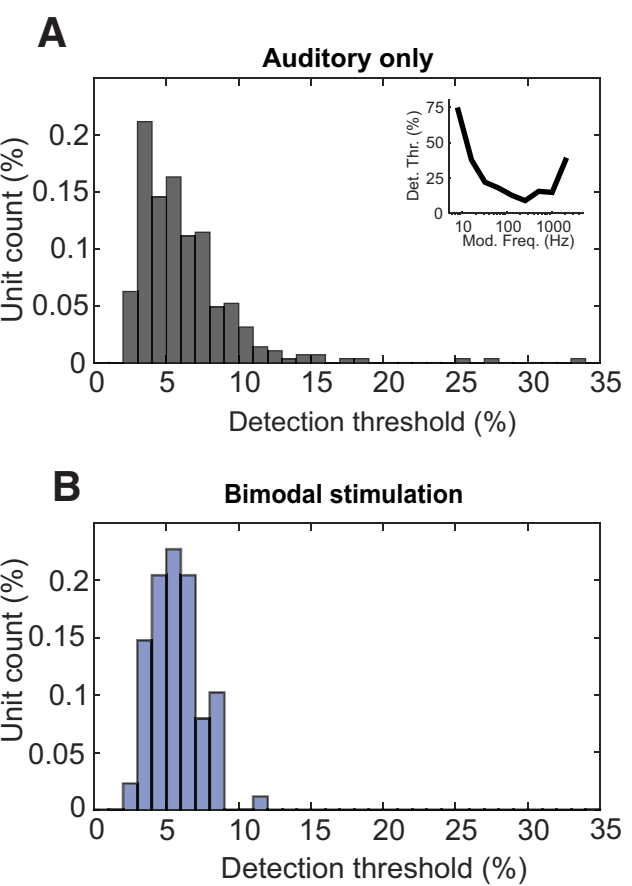

Figure 6. Effects of bimodal integration on AM detection thresholds. $A$, Histogram of all best AM detection thresholds for PL units either before bimodal auditory-Sp5 stimulation or before auditory sham stimulation ( $n=288$; mean, $6.5 \%$; range, $2.5-33.1 \%$; SD, 4.1\%). The inset shows a representative detection threshold curve of a Pri unit, with a best detection frequency at $256 \mathrm{~Hz}$ and a best detection threshold at $9.0 \%$. $\boldsymbol{B}$, Histogram of all best modulation detection thresholds during bimodal auditory-Sp5 stimulation.

significantly shifted to lower frequencies when evaluated 45 min after bimodal auditory-Sp5 stimulation $\left(t_{(119)}=2.97, p=0.004\right.$; Fig. $7 F$ ). However, this change was not as pronounced as observed for bimodal integration and some units previously tuned to a low BMF $(<100 \mathrm{~Hz})$ shifted upward to a higher BMF after bimodal auditory-Sp5 stimulation (Fig. $7 F$ ).

In summary, these results indicate that bimodal auditorysomatosensory stimulation strengthened neural coding of the lower modulation frequencies over time.

Figure $8 A$ shows a representative example of a bushy cell AM detection threshold curve before (blue line) and $45 \mathrm{~min}$ after (red line) bimodal auditory-Sp5 stimulation. Detection thresholds were improved over the complete range of modulation frequencies.

Across the population of units, AM detection thresholds were similarly improved 45 min after bimodal auditory-Sp5 stimulation (Fig. 8B). To control for natural fluctuations of AM detection thresholds over time, we compared change in detection thresholds following bimodal auditory-Sp5 stimulation with change in detection thresholds after an auditory sham condition in which AM-only stimuli replaced auditory-Sp5 AM stimuli. Long-term alterations of detection thresholds were indeed observed after bimodal auditory-Sp5 stimulation compared with the $95 \%$ confidence interval of the sham condition (dashed lines in Fig. $8 B$ ), where improvements $(n=18 / 120)$ occurred more frequently than deteriorations $(n=5 / 120)$. Compared with the sham condition, bimodal auditory-Sp5 stimulation resulted in a significant long-term improvement of detection thresholds $\left(\chi^{2}\right.$ test: $\left.\chi_{(2)}^{2}=10.562, p=0.005\right)$. These results show that AM detection thresholds are improved 45 min after bimodal auditory-Sp5 stimulation.

\section{Sp5 innervates inhibitory interneurons that project to bushy cells}

Bushy cell auditory-Sp5 integration may have been facilitated by VCN D-stellate cells, which are interneurons that provide wideband inhibition to bushy cells (Campagnola and Manis, 2014). Injecting an anterograde tracer in Sp5 and a retrograde tracer in the contralateral $\mathrm{CN}$ demonstrated that $\mathrm{D}$-stellate cells receive axodendritic terminals from $\mathrm{Sp} 5$. Figure $9 A$ shows a representative example of a $\mathrm{Sp} 5$ putative terminal located on the dendrites of a retrogradely labeled D-stellate cell (via the CN commissural projection).

Furthermore, recordings from 42 putative D-stellate cells, identified by typical On-C responses to BF tones (Fig. $9 B$, inset), verify that these cells responded to Sp5 stimulation. In 70\% (29/42) of On-C units, Sp5 stimulation resulted in a multiple-peaked excitatory responses (see Fig. $9 B$ for a representative example). No single-peaked or inhibitory responses were observed in On-C units. Mean response latency to $\mathrm{Sp} 5$ stimulation was $3.8 \pm 0.11$ ms (SEM), which was comparable to the excitatory response latency in PL units.

Therefore, Sp5-to-D-stellate cell projections likely contributed to the enhanced temporal responses and improved detection thresholds in bushy cells induced by bimodal auditory-Sp5 stimulation.

\section{Discussion}

The current study demonstrated for the first time that Sp5 projects to bushy cell and D-stellate cell dendritic fields and, when stimulated, elicited unimodal excitatory responses in both cell types. Furthermore, bimodal auditory-somatosensory stimulation decreased BMF and increased synchronization indices for modulation frequencies below the initial BMF in bushy cells. These changes persisted for up to $45 \mathrm{~min}$. Furthermore, AM detection thresholds were significantly improved $45 \mathrm{~min}$ after bimodal auditory-Sp5 stimulation, but not during the bimodal auditory-Sp5 stimulation. Therefore, bimodal auditory-Sp5 stimulation resulted in both enhancement of responses to AM stimuli and improvements in AM sensitivity of bushy cells in the VCN.

Because of the large axosomatic projections from the auditory nerve (Tolbert and Morest, 1982; Ryugo and Sento, 1991), bushy cells are sometimes regarded as simple relay neurons. However, bushy cells also receive noncochlear excitatory and inhibitory projections (Zhou et al., 2007; Gómez-Nieto and Rubio, 2009). Recent studies have demonstrated robust inhibitory responses in bushy cells (Kopp-Scheinpflug et al., 2002; Gai and Carney, 2008; Keine and Rübsamen, 2015). The current study is the first to show the function of noncochlear excitatory axodendritic inputs on bushy cells and D-stellate cells and advances our expanding knowledge on the role of PL units in hearing.

\section{Sp5 terminates in bushy cell dendritic fields}

Anterograde injections resulted in labeled terminal endings, demonstrating that Sp5 projects to the magnocellular domain of the $\mathrm{VCN}$, confirming previous studies in guinea pigs and rats (Zhou and Shore, 2004; Haenggeli et al., 2005). Furthermore, the retrograde tracer injections placed in SOC to backfill bushy cells and in contralateral CN to backfill D-stellate cells enabled us to refine the locations of the Sp5 terminals on bushy cell and D-stellate cell dendritic fields.

Evidence that Sp5 innervates bushy cells is supported by several observations. First, bushy cells showed short $(3.8 \mathrm{~ms})$ response latencies to unimodal Sp5 stimulation, which is consistent 
A

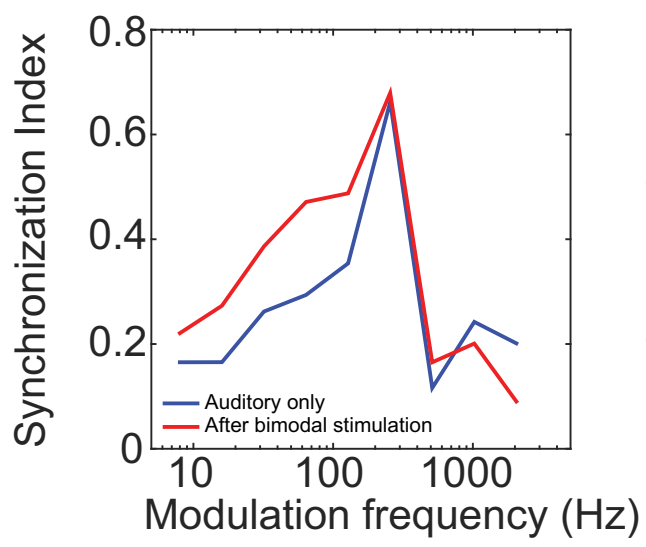

C

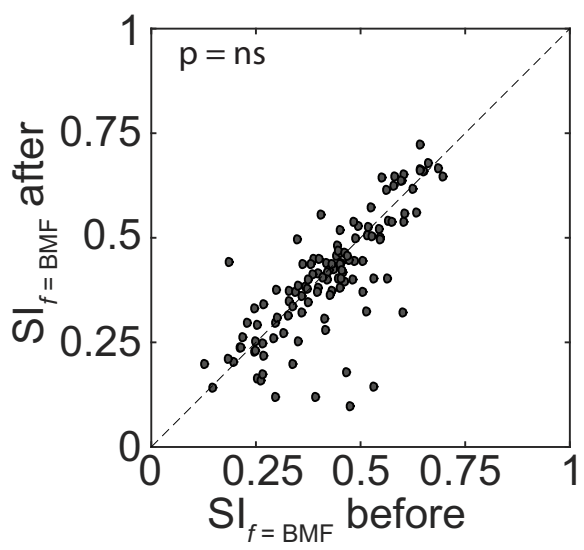

$\mathbf{E}$

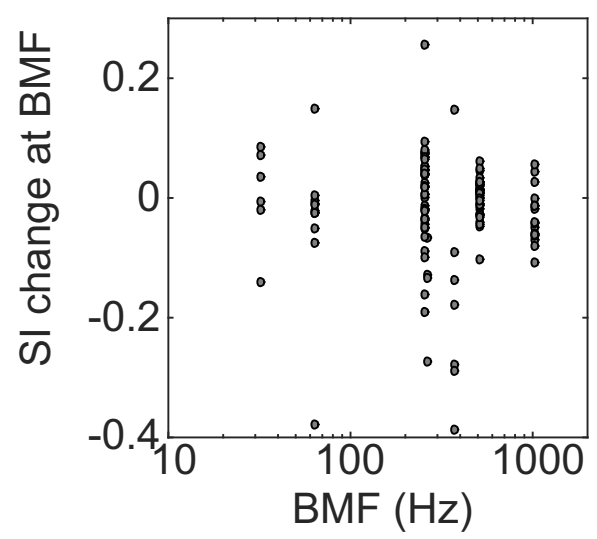

B

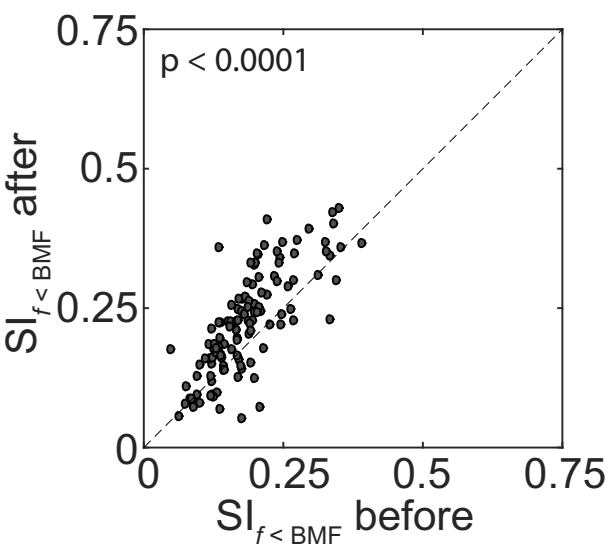

D

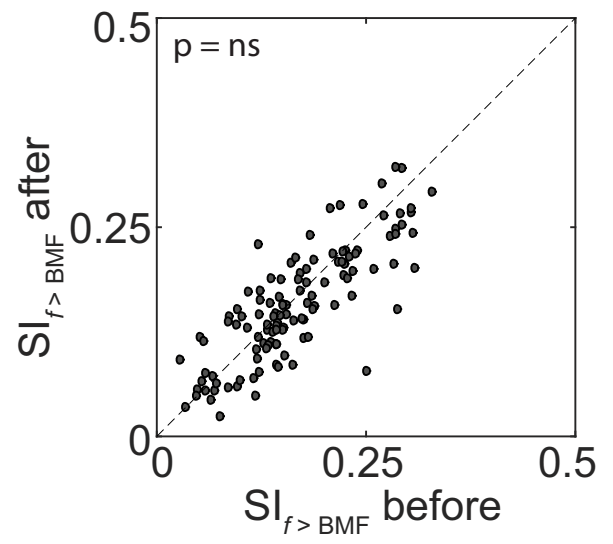

$\mathbf{F}$

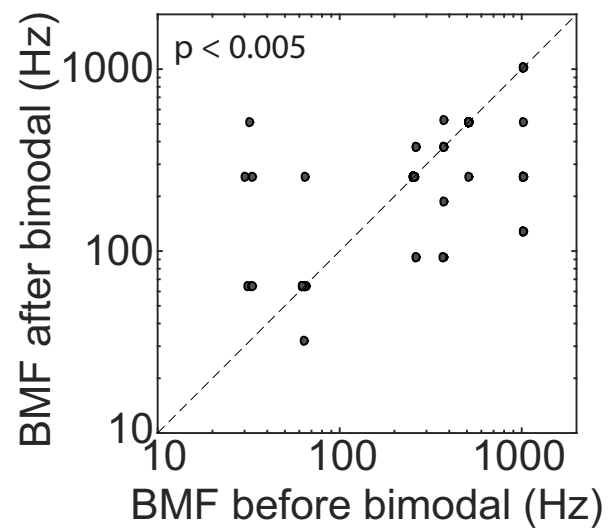

Figure 7. Effects of bimodal plasticity on the MTF. A, Representative example of a Pri unit MTF before (blue line) and 45 min after bimodal auditory-Sp5 stimulation (red line). $\boldsymbol{B}$, Mean SI plotted against mean SI after bimodal auditory-Sp5 stimulation for frequencies below BMF. C, SI at BMF plotted against SI at BMF after bimodal auditory-Sp5 stimulation. D, Mean SI plotted against mean Sl after bimodal auditory-Sp5 stimulation for frequencies above BMF. E, BMF plotted against the change in SI at BMF. $F$, BMF plotted against BMF during bimodal auditory-Sp5 stimulation. Black dotted lines in $\boldsymbol{B}-\boldsymbol{D}$ and $\boldsymbol{F}$ represent $y=x$. $p$-values depicted in the graphs indicate significance after one-sample $t$ tests and are corrected for multiple comparisons using the Holm-Bonferroni correction.

with a single synapse latency. In contrast, fusiform cells in the DCN have much longer latencies to Sp5 stimulation (ranging from 6 to $11.5 \mathrm{~ms}$ ) (Shore et al., 2008; Koehler et al., 2011), which can be attributed to the additional Sp5-to-granule cell synapse and subsequent traveling through the granule cell's unmyelinated axon (i.e., the parallel fiber) (Oertel and Young, 2004; Shore, 2005). Second, the Sp5-to-VCN projection is glutamatergic, co- labeling with VGLUT2 (Zhou et al., 2007; Zeng et al., 2011), and bushy cells receive VGLUT2-positive terminals on their cell bodies and dendritic trees (Gómez-Nieto and Rubio, 2009). These glutamatergic terminals can be distinguished from AN glutamatergic endings, which colabel instead with VGLUT1 (Zhou et al., 2007). Finally, Sp5 projects also to the rostral area of the VCN, which contains predominantly bushy cells (Hackney et al., 1990), 
A

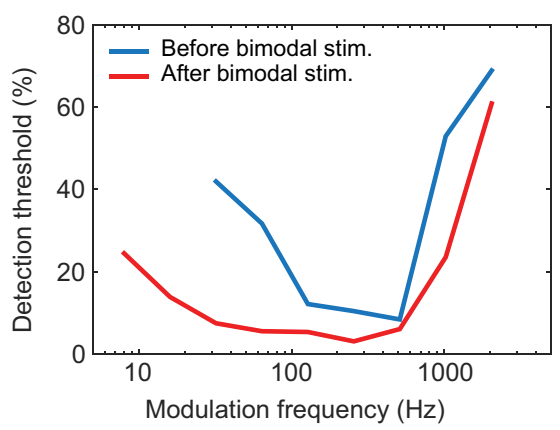

B

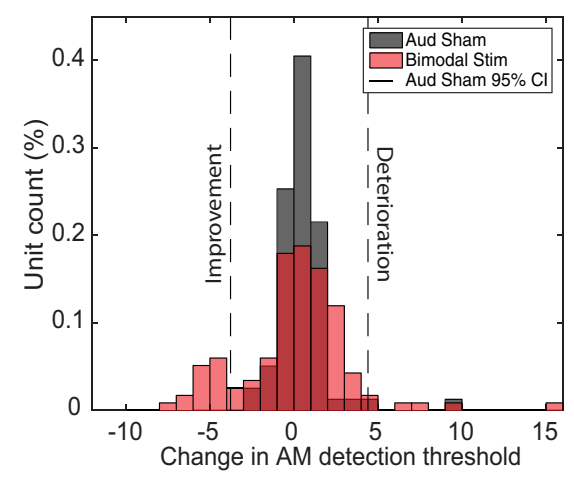

Figure 8. Effects of bimodal plasticity on AM detection thresholds. A, Representative example of improvements along the AM detection threshold curve after bimodal auditory-Sp5 stimulation of a Pri unit. B, Absolute change in best AM detection thresholds for the sham (gray) and the bimodal auditory-Sp5 stimulation (dark red) groups. Dashed lines indicate the $95 \%$ confidence intervals for the sham group and represent the range of fluctuation in the best detection threshold expected based on natural changes over time.

indicating that $\mathrm{Sp} 5$ projects directly onto bushy cells in that region. However, because the average $\mathrm{BF}$ of units responding to Sp5 stimulation was relatively high $(13 \mathrm{kHz} \pm 1.15$ SEM), bushy cells outside of the most rostral region of VCN likely receive Sp5 projections as well.

A small portion of the anterograde labeled projections may have originated in the cuneate nucleus because the diffusion area of the injection site partly infringed the cuneate nucleus, which also projects to the CN (Wright and Ryugo, 1996; Li and Mizuno, 1997), with a similar projection pattern as the Sp5 (Zeng et al., 2011).

\section{Bimodal auditory-Sp5 stimulation influences bushy cell responses to AM stimuli}

Although controversial (Blackburn and Sachs, 1989; Winter and Palmer, 1990), several studies demonstrate that bushy cells encode temporal information with high precision, with better phase locking than their input source, the AN (Frisina et al., 1990b; Joris et al., 1994b; Recio-Spinoso, 2012; Keine and Rübsamen, 2015). Coincidence detection may play an important role in the phaselocking enhancement in bushy cells. Because end bulbs from multiple AN fibers synapse on the bushy cell soma (Sento and Ryugo, 1989; Ryugo and Sento, 1991) and because bushy cells exhibit short membrane time constants (Oertel, 1983; Wu and Oertel, 1984), only spikes arriving simultaneously from multiple AN fibers will elicit a spike in the bushy cell (Joris et al., 1994b). Such coincidence detection is likely enhanced by activation of presynaptic inhibitory receptors (Frisina et al., 1990a; Chanda
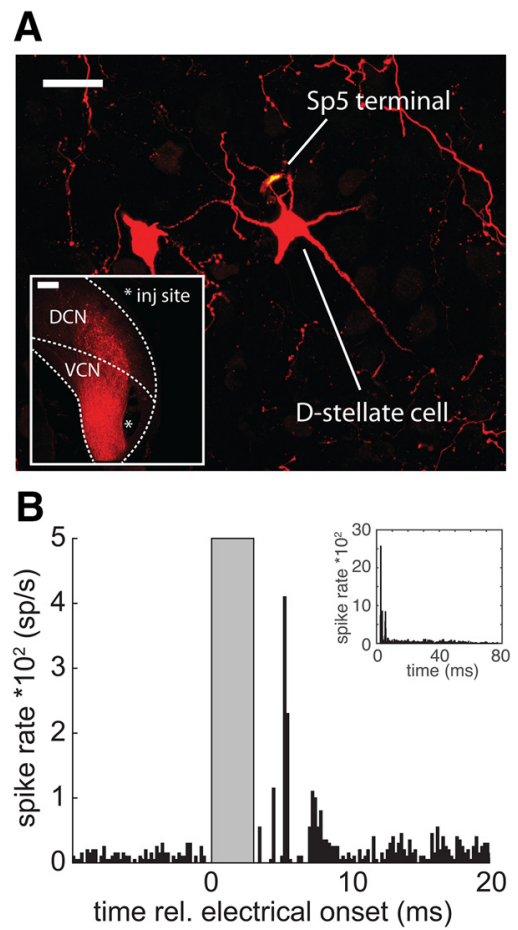

Figure 9. Sp5 innervates D-stellate cells in the VCN. $\boldsymbol{A}, \mathrm{D}$-stellate cells are retrogradely labeled via tracer injection in the contralateral CN (inset; scale bar, $300 \mu \mathrm{m}$ ). A representative confocal photomicrograph shows Sp5 (green fluorescence, same procedure as described in Fig. 2; merged in yellow) projecting to a D-stellate cell (red; scale bar, $30 \mu \mathrm{m}$ ) in the VCN. $\boldsymbol{B}$, PSTH of an On-C unit response to electrical Sp5 stimulation ( $60 \mu \mathrm{A}$ current pulses; $0.2 \mathrm{~ms}$ bin width). The gray bar indicates the $\mathrm{Sp} 5$ stimulus duration. The absence of neural activity from $0-2.2 \mathrm{~ms}$ is due to electrical artifact removal. Inset shows the unit's onset chopper discharge pattern to a tone burst at BF (50 ms tone at $6.9 \mathrm{kHz}$ at $30 \mathrm{~dB}$ re threshold, $0.2 \mathrm{~ms}$ bin width).

and Xu-Friedman, 2010; Dehmel et al., 2010; Wang et al., 2011; Keine and Rübsamen, 2015) because blocking inhibition decreases synchrony in bushy cells (Gai and Carney, 2008). Moreover, increased inhibitory strength shifts the bushy cell MTF toward lower modulation frequencies and higher synchronization indices in an auditory brainstem model (Eguia et al., 2010), consistent with the increased synchronization indices especially at low modulation frequencies reported in the current study.

D-stellate cells provide one source of that inhibitory input to bushy cells (Campagnola and Manis, 2014). Here, we showed also that Sp5 projects to the dendrites of these D-stellate cells. Furthermore, 70\% of On-C units, which likely represent responses from D-stellate cells (Smith and Rhode, 1989), showed an excitatory response upon electrical stimulation of Sp5. It is therefore possible that Sp5 terminals activate these inhibitory interneurons in the $\mathrm{CN}$, which in turn inhibit bushy cells to sharpen phase locking after bimodal auditory-Sp5 stimulation. This Sp5-driven inhibitory input to bushy cells was subthreshold because no inhibitory responses to unimodal Sp5 stimulation were observed in PL units.

An alternative mechanism by which multisensory influences on bushy cells could occur is by influencing reciprocal connections between bushy cells, which may facilitate enhanced bushy cell synchronization to the stimulus temporal fluctuations (Gómez-Nieto and Rubio, 2009).

Unimodal responses to Sp5 stimulation were observed in only a subset of bushy cells. This may indicate that not all bushy cells 
receive direct Sp5 innervation, in agreement with the sparse projection pattern of $\mathrm{Sp} 5$ terminals to the magnocellular region of the VCN (Zhou and Shore, 2004; Haenggeli et al., 2005). However, bimodal auditory-Sp5 stimulation affected most PL units, suggesting that Sp5 input to bushy cells was subthreshold for a large number of bushy cells becoming apparent only upon simultaneous activation of the auditory and somatosensory system.

Long-term plasticity was induced by bimodal auditory-Sp5 stimulation in bushy cells, as demonstrated by enhanced or improved temporal coding that remained or became apparent 45 min after bimodal stimulation. This time course is consistent with the finding that most Sp5 terminals in the VCNm are en passant boutons, which are thought to have a modulatory rather than a direct activation function (Zeng et al., 2011). This modulatory function implies that Sp5-derived glutamate may act on metabotropic glutamate bushy cell receptors (mGluRs). Indeed, mGluRs on bushy cells are tonically active and are highly sensitive to ambient glutamate, which affects firing probabilities and interacts with inhibitory modulatory systems (Chanda and Xu-Friedman, 2010).

\section{Implications of improved temporal coding in bushy cells}

The current study showed that bimodal auditory-somatosensory stimulation enhanced phase locking to low-frequency AM stimuli in VCN bushy cells. Enhancement of neural activity in humans, as measured by fMRI and EEG, occurs during multimodal stimulation compared with unimodal stimulation (Calvert et al., 2000; Foxe et al., 2000; Macaluso et al., 2000; Murray et al., 2005; Nozaradan et al., 2012). These enhanced neural responses improve perception; for example, intensity discrimination of an auditory stimulus is improved when concurrently presented with a somatosensory stimulus (Schürmann et al., 2004; Gillmeister and Eimer, 2007; Wilson et al., 2010). Therefore, enhanced phase locking in bushy cells by bimodal auditory-somatosensory stimulation could explain increases in the salience of an auditory signal.

Improved AM detection thresholds in bushy cells after bimodal auditory-Sp5 stimulation are in agreement with human studies. For example, speech perception thresholds of hearing-impaired children are improved when hearing aids are used in concert with the Tickle Talker, an electrotactile speech processor (Galvin et al., 1991), and auditory detection thresholds are improved in the presence of a tactile cue (Gillmeister and Eimer, 2007). Furthermore, AM detection thresholds of bushy cells reported in the current study closely resemble AM detection thresholds of normal-hearing human listeners (Viemeister, 1979; Forrest and Green, 1987; Sheft and Yost, 1990), suggesting that bushy cells play an important role in neural processing and detection of amplitude modulations. Therefore, the improved AM detection thresholds with bimodal auditory-Sp5 stimulation may translate to improved behavioral AM detection.

Bushy cells are the primary input to the SOC (Smith et al., 1991; Smith et al., 1993; Cant and Benson, 2003), which is involved in sound localization in the horizontal plane and relies on accurate temporal information. Therefore, the current study suggests that the Sp5-to-bushy cell projection may aid in azimuthal sound localization by improving detection and representation of temporal modulations. Furthermore, temporal modulations comprise an important feature of biologically relevant acoustic stimuli, including communication signals, such as speech (Rosen, 1992; Colletti and Shannon, 2005), suggesting an important role for bushy cells in processing communication signals. Improvement of bushy cell AM coding by bimodal auditory-somatosensory stimulation, such as shown in the current study, may thus be involved in priming the neurons for coding of biologically relevant sounds.

\section{References}

Alais D, Newell FN, Mamassian P (2010) Multisensory processing in review: from physiology to behaviour. Seeing Perceiving 23:3-38. CrossRef Medline

Barker M, Solinski HJ, Hashimoto H, Tagoe T, Pilati N, Hamann M (2012) Acoustic overexposure increases the expression of VGLUT-2 mediated projections from the lateral vestibular nucleus to the dorsal cochlear nucleus. PLoS One 7:e35955. CrossRef Medline

Blackburn CC, Sachs MB (1989) Classification of unit types in the anteroventral cochlear nucleus: PST histograms and regularity analysis. J Neurophysiol 62:1303-1329. CrossRef Medline

Bolognini N, Frassinetti F, Serino A, Làdavas E (2005) “Acoustical vision” of below threshold stimuli: interaction among spatially converging audiovisual inputs. Exp Brain Res 160:273-282. CrossRef Medline

Caclin A, Bouchet P, Djoulah F, Pirat E, Pernier J, Giard MH (2011) Auditory enhancement of visual perception at threshold depends on visual abilities. Brain Res 1396:35-44. CrossRef Medline

Calvert GA, Campbell R, Brammer MJ (2000) Evidence from functional magnetic resonance imaging of crossmodal binding in the human heteromodal cortex. Curr Biol 10:649-657. Medline

Campagnola L, Manis PB (2014) A map of functional synaptic connectivity in the mouse anteroventral cochlear nucleus. J Neurosci 34:2214-2230. CrossRef Medline

Cant NB, Benson CG (2003) Parallel auditory pathways: projection patterns of the different neuronal populations in the dorsal and ventral cochlear nuclei. Brain Res Bull 60:457-474. CrossRef Medline

Chanda S, Xu-Friedman MA (2010) Neuromodulation by GABA converts a relay into a coincidence detector. J Neurophysiol 104:2063-2074. CrossRef Medline

Chase SM, Young ED (2007) First-spike latency information in single neurons increases when referenced to population onset. Proc Natl Acad Sci U S A 104:5175-5180. CrossRef Medline

Colletti V, Shannon RV (2005) Open set speech perception with auditory brainstem implant? Laryngoscope 115:1974-1978. CrossRef Medline

Dehmel S, Kopp-Scheinpflug C, Weick M, Dörrscheidt GJ, Rübsamen R (2010) Transmission of phase-coupling accuracy from the auditory nerve to spherical bushy cells in the mongolian gerbil. Hear Res 268:234249. CrossRef Medline

Eguia MC, Garcia GC, Romano SA (2010) A biophysical model for modulation frequency encoding in the cochlear nucleus. J Physiol (Paris) 104: 118-127. CrossRef Medline

Forrest TG, Green DM (1987) Detection of partially filled gaps in noise and the temporal modulation transfer function. J Acoust Soc Am 82:19331943. CrossRef Medline

Foxe JJ, Morocz IA, Murray MM, Higgins BA, Javitt DC, Schroeder CE (2000) Multisensory auditory-somatosensory interactions in early cortical processing revealed by high-density electrical mapping. Brain Res Cogn Brain Res 10:77-83. CrossRef Medline

Frassinetti F, Bolognini N, Làdavas E (2002) Enhancement of visual perception by crossmodal visuo-auditory interaction. Exp Brain Res 147:332343. CrossRef Medline

Frisina RD, Smith RL, Chamberlain SC (1990a) Encoding of amplitude modulation in the gerbil cochlear nucleus: II. Possible neural mechanisms. Hear Res 44:123-141. CrossRef Medline

Frisina RD, Smith RL, Chamberlain SC (1990b) Encoding of amplitude modulation in the gerbil cochlear nucleus: I. A hierarchy of enhancement. Hear Res 44:99-122. CrossRef Medline

Gai Y, Carney LH (2008) Influence of inhibitory inputs on rate and timing of responses in the anteroventral cochlear nucleus. J Neurophysiol 99: 1077-1095. CrossRef Medline

Galvin KL, Cowan RS, Sarant JZ, Alcántara JI, Blamey PJ, Clark GM (1991) Use of a multichannel electrotactile speech processor by profoundly hearing-impaired children in a total communication environment. J Am Acad Audiol 2:214-225. Medline

Gillmeister H, Eimer M (2007) Tactile enhancement of auditory detection and perceived loudness. Brain Res 1160:58-68. CrossRef Medline

Goldberg JM, Brown PB (1969) Response of binaural neurons of dog superior olivary complex to dichotic tonal stimuli: some physiological 
mechanisms of sound localization. J Neurophysiol 32:613-636. CrossRef Medline

Gómez-Nieto R, Rubio ME (2009) A bushy cell network in the rat ventral cochlear nucleus. J Comp Neurol 516:241-263. CrossRef Medline

Hackney CM, Osen KK, Kolston J (1990) Anatomy of the cochlear nuclear complex of guinea pig. Anat Embryol (Berl) 182:123-149. Medline

Haenggeli CA, Pongstaporn T, Doucet JR, Ryugo DK (2005) Projections from the spinal trigeminal nucleus to the cochlear nucleus in the rat. J Comp Neurol 484:191-205. CrossRef Medline

Hayashi H (1980) Distributions of vibrissae afferent fiber collaterals in the trigeminal nuclei as revealed by intra-axonal injection of horseradish peroxidase. Brain Res 183:442-446. CrossRef Medline

Ingham NJ, Itatani N, Bleeck S, Winter IM (2016) Enhancement of forward suppression begins in the ventral cochlear nucleus. Brain Res 1639:13-27. CrossRef Medline

Joris PX, Smith PH, Yin TC (1994a) Enhancement of neural synchronization in the anteroventral cochlear nucleus. II. Responses in the tuning curve tail. J Neurophysiol 71:1037-1051. CrossRef Medline

Joris PX, Carney LH, Smith PH, Yin TC (1994b) Enhancement of neural synchronization in the anteroventral cochlear nucleus. I. Responses to tones at the characteristic frequency. J Neurophysiol 71:1022-1036. CrossRef Medline

Joris PX, Schreiner CE, Rees A (2004) Neural processing of amplitudemodulated sounds. Physiol Rev 84:541-577. CrossRef Medline

Kanold PO, Young ED (2001) Proprioceptive information from the pinna provides somatosensory input to cat dorsal cochlear nucleus. J Neurosci 21:7848-7858. Medline

Keine C, Rübsamen R (2015) Inhibition shapes acoustic responsiveness in spherical bushy cells. J Neurosci 35:8579-8592. CrossRef Medline

Koehler SD, Shore SE (2013) Stimulus-timing dependent multisensory plasticity in the guinea pig dorsal cochlear nucleus. PLoS One 8:e59828. CrossRef Medline

Koehler SD, Pradhan S, Manis PB, Shore SE (2011) Somatosensory inputs modify auditory spike timing in dorsal cochlear nucleus principal cells. Eur J Neurosci 33:409-420. CrossRef Medline

Kopp-Scheinpflug C, Dehmel S, Dörrscheidt GJ, Rübsamen R (2002) Interaction of excitation and inhibition in anteroventral cochlear nucleus neurons that receive large endbulb synaptic endings. J Neurosci 22: 11004-11018. Medline

Lakatos P, Chen CM, O'Connell MN, Mills A, Schroeder CE (2007) Neuronal oscillations and multisensory interaction in primary auditory cortex. Neuron 53:279-292. CrossRef Medline

Li H, Mizuno N (1997) Single neurons in the spinal trigeminal and dorsal column nuclei project to both the cochlear nucleus and the inferior colliculus by way of axon collaterals: a fluorescent retrograde double-labeling study in the rat. Neurosci Res 29:135-142. CrossRef Medline

Macaluso E, Frith CD, Driver J (2000) Modulation of human visual cortex by crossmodal spatial attention. Science 289:1206-1208. CrossRef Medline

Mardia KV, Jupp PE (2000) Directional statistics. New York: Wiley.

Murray MM, Molholm S, Michel CM, Heslenfeld DJ, Ritter W, Javitt DC, Schroeder CE, Foxe JJ (2005) Grabbing your ear: rapid auditory-somatosensory multisensory interactions in low-level sensory cortices are not constrained by stimulus alignment. Cereb Cortex 15:963-974. CrossRef Medline

Nozaradan S, Peretz I, Mouraux A (2012) Steady-state evoked potentials as an index of multisensory temporal binding. Neuroimage 60:21-28. CrossRef Medline

Oertel D (1983) Synaptic responses and electrical properties of cells in brain slices of the mouse anteroventral cochlear nucleus. J Neurosci 3:20432053. Medline

Oertel D, Young ED (2004) What's a cerebellar circuit doing in the auditory system? Trends Neurosci 27:104-110. CrossRef Medline

Osen KK (1969) Cytoarchitecture of the cochlear nuclei in the cat. J Comp Neurol 136:453-484. CrossRef Medline

Recio-Spinoso A (2012) Enhancement and distortion in the temporal representation of sounds in the ventral cochlear nucleus of chinchillas and cats. PLoS One 7:e44286. CrossRef Medline

Rhode WS, Oertel D, Smith PH (1983) Physiological response properties of cells labeled intracellularly with horseradish peroxidase in cat ventral cochlear nucleus. J Comp Neurol 213:448-463. CrossRef Medline

Rosen S (1992) Temporal information in speech: acoustic, auditory and linguistic aspects. Philos Trans R Soc Lond B Biol Sci 336:367-373. CrossRef Medline

Rouiller EM, Ryugo DK (1984) Intracellular marking of physiologically characterized cells in the ventral cochlear nucleus of the cat. J Comp Neurol 225:167-186. CrossRef Medline

Ryugo DK, Sento S (1991) Synaptic connections of the auditory nerve in cats: relationship between endbulbs of held and spherical bushy cells. J Comp Neurol 305:35-48. CrossRef Medline

Sayles M, Füllgrabe C, Winter IM (2013) Neurometric amplitude-modulation detection threshold in the guinea-pig ventral cochlear nucleus. J Physiol 591:3401-3419. CrossRef Medline

Schofield BR, Cant NB (1996) Origins and targets of commissural connections between the cochlear nuclei in guinea pigs. J Comp Neurol 375:128146. CrossRef Medline

Schürmann M, Caetano G, Jousmäki V, Hari R (2004) Hands help hearing: facilitatory audiotactile interaction at low sound-intensity levels. J Acoust Soc Am 115:830 - 832. CrossRef Medline

Sento S, Ryugo DK (1989) Endbulbs of held and spherical bushy cells in cats: morphological correlates with physiological properties. J Comp Neurol 280:553-562. CrossRef Medline

Shannon RV, Zeng FG, Kamath V, Wygonski J, Ekelid M (1995) Speech recognition with primarily temporal cues. Science 270:303-304. CrossRef Medline

Sheft S, Yost WA (1990) Temporal integration in amplitude modulation detection. J Acoust Soc Am 88:796-805. CrossRef Medline

Shore SE (2005) Multisensory integration in the dorsal cochlear nucleus: unit responses to acoustic and trigeminal ganglion stimulation. Eur J Neurosci 21:3334-3348. CrossRef Medline

Shore SE, Koehler S, Oldakowski M, Hughes LF, Syed S (2008) Dorsal cochlear nucleus responses to somatosensory stimulation are enhanced after noise-induced hearing loss. Eur J Neurosci 27:155-168. CrossRef Medline

Smith PH, Rhode WS (1987) Characterization of HRP-labeled globular bushy cells in the cat anteroventral cochlear nucleus. J Comp Neurol 266:360-375. CrossRef Medline

Smith PH, Rhode WS (1989) Structural and functional properties distinguish two types of multipolar cells in the ventral cochlear nucleus. J Comp Neurol 282:595-616. CrossRef Medline

Smith PH, Joris PX, Carney LH, Yin TC (1991) Projections of physiologically characterized globular bushy cell axons from the cochlear nucleus of the cat. J Comp Neurol 304:387-407. CrossRef Medline

Smith PH, Joris PX, Yin TC (1993) Projections of physiologically characterized spherical bushy cell axons from the cochlear nucleus of the cat: evidence for delay lines to the medial superior olive. J Comp Neurol 331:245-260. CrossRef Medline

Sperdin HF, Cappe C, Foxe JJ, Murray MM (2009) Early, low-level auditory-somatosensory multisensory interactions impact reaction time speed. Front Integr Neurosci 3:2. CrossRef Medline

Stein BE, Stanford TR (2008) Multisensory integration: current issues from the perspective of the single neuron. Nat Rev Neurosci 9:255-266. CrossRef Medline

Stein BE, London N, Wilkinson LK, Price DD (1996) Enhancement of perceived visual intensity by auditory stimuli: a psychophysical analysis. J Cogn Neurosci 8:497-506. CrossRef Medline

Tolbert LP, Morest DK (1982) The neuronal architecture of the anteroventral cochlear nucleus of the cat in the region of the cochlear nerve root: golgi and nissl methods. Neuroscience 7:3013-3030. CrossRef Medline

van Ham JJ, Yeo CH (1996) Trigeminal inputs to eyeblink motoneurons in the rabbit. Exp Neurol 142:244-257. CrossRef Medline

Viemeister NF (1979) Temporal modulation transfer functions based upon modulation thresholds. J Acoust Soc Am 66:1364-1380. CrossRef Medline

Wang Y, O'Donohue H, Manis P (2011) Short-term plasticity and auditory processing in the ventral cochlear nucleus of normal and hearing-impaired animals. Hear Res 279:131-139. CrossRef Medline

Wilson EC, Braida LD, Reed CM (2010) Perceptual interactions in the loudness of combined auditory and vibrotactile stimuli. J Acoust Soc Am 127:3038-3043. CrossRef Medline

Winter IM, Palmer AR (1990) Responses of single units in the anteroventral cochlear nucleus of the guinea pig. Hear Res 44:161-178. CrossRef Medline

Winter IM, Palmer AR (1995) Level dependence of cochlear nucleus onset unit responses and facilitation by second tones or broadband noise. J Neurophysiol 73:141-159. CrossRef Medline 
Wright DD, Ryugo DK (1996) Mossy fiber projections from the cuneate nucleus to the cochlear nucleus in the rat. J Comp Neurol 365:159-172. CrossRef Medline

Wu C, Stefanescu RA, Martel DT, Shore SE (2016) Tinnitus: maladaptive auditory-somatosensory plasticity. Hear Res 334:20-29. CrossRef Medline

Wu SH, Oertel D (1984) Intracellular injection with horseradish peroxidase of physiologically characterized stellate and bushy cells in slices of mouse anteroventral cochlear nucleus. J Neurosci 4:1577-1588. Medline

Young ED, Robert JM, Shofner WP (1988) Regularity and latency of units in ventral cochlear nucleus: implications for unit classification and generation of response properties. J Neurophysiol 60:1-29. CrossRef Medline

Zeng C, Shroff H, Shore SE (2011) Cuneate and spinal trigeminal nucleus projections to the cochlear nucleus are differentially associated with vesicular glutamate transporter-2. Neuroscience 176:142-151. CrossRef Medline

Zhou J, Shore S (2004) Projections from the trigeminal nuclear complex to the cochlear nuclei: a retrograde and anterograde tracing study in the guinea pig. J Neurosci Res 78:901-907. CrossRef Medline

Zhou J, Nannapaneni N, Shore S (2007) Vesicular glutamate transporters 1 and 2 are differentially associated with auditory nerve and spinal trigeminal inputs to the cochlear nucleus. J Comp Neurol 500:777-787. CrossRef Medline 